\title{
Self-Cleaning Concrete for Landscaping Applications
}

\author{
Diana-Maria Mircea ${ }^{1, *}$ \\ ${ }^{1}$ University of Agricultural Sciences and Veterinary Medicine of Cluj-Napoca, 400372 Cluj-Napoca, Romania
}

\begin{abstract}
Negative effects of environmental pollution pose a significant risk to agriculture, water resources and human health. This can however be reduced by selecting appropriate materials in construction and landscape architecture. It is well-known that strong sunlight or ultraviolet light decomposes many organic materials in a slow natural process. Photocatalytic substances accelerate this process and when used in concrete (which is one of the most widely used construction materials), permit the treatment of pollutants close to their source by applying a self-cleaning principle: decomposing organic materials, biological materials and pollutants into molecules like oxygen, water, carbon dioxide, nitrates, and sulphates. Catalytic material activation will start due to energy that is received from sunlight (it also can be activated using artificial lights), and selfcleaning begins when this material is activated. Beside other properties, this innovative self-cleaning concrete also keeps its colour for far longer than other traditional building materials, making it a desirable solution for landscaping applications.
\end{abstract}

\section{Introduction}

People are more aware nowadays of the importance of preserving the environment. In a modern urban environment, green spaces often serve as isles of habitat for native species of plants, insects, birds and small animals. In densely populated areas, landscape architecture provides outdoor recreation areas within aesthetically pleasing and culturally meaningful sceneries that increase the life quality and enhance the well-being of local population.

All industrialized places and densely populated urban areas have problems with pollution. Factories are essential to provide a source of economic growth but also have negative effects on the environment. Environmental pollution poses a significant risk to agriculture, water resources and human health. This can however be reduced by selecting appropriate materials in construction and landscape architecture.

Structural and decorative concrete elements, covering a large variety of shapes and colours, are used in landscaping in order to expand the design possibilities when putting into practice new architectural solutions.

A photocatalyst is a semiconducting substance [1] which can be chemically activated by light radiation that results in an oxidation-reduction reaction. The application of photocatalysts in concrete technology is by now a well-established concept. Starting in the late 1960s [2], the research on titanium dioxide $\left(\mathrm{TiO}_{2}\right)$ began with photoelectrochemical solar energy conversion, then through the area of environmental photocatalysis, including self-cleaning surfaces, and nowadays it has emerged as an excellent photocatalyst material for environmental purification.

\section{Properties of self-cleaning concrete}

Landscape compositions create harmonious combinations of natural and artificial elements of the environment (Figure 1), in accordance with certain artistic expertise into a holistic spatial design able to improve the location and to develop recreational facilities, both efficient and inspired. A contribution to regeneration of polluted areas can be achieved through landscaping applications, especially if resourceful materials and methods are implemented.

Self-Cleaning Concrete is an innovative construction material that has been developed in the past decades providing the "self cleaning" ability of concrete surfaces, by retaining their light colour for longer, along with the property to remove airborne toxins, particularly nitrogen oxides. The reactions begin when the catalytic material added to concrete is activated, due to sunlight, or artificial light with similar properties (e.g. ultraviolet light).

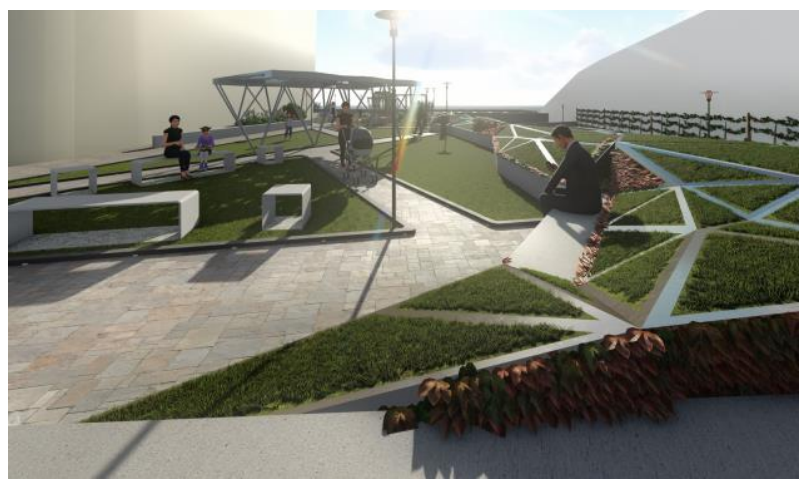

Fig. 1. Landscape composition with concrete elements. 
Since strong sunlight decomposes many organic materials in a slow natural process, photocatalysts accelerate this process, and stimulate the chemical transformation without being consumed by the reaction. To increase the efficiency of photocatalysts, they must be accessible to sunlight and activated, so their presence on the surface of the material is essential [3]. When used in concrete, they decompose organic materials like oil and silt, biological materials (mould, algae and bacteria) and pollutants such as volatile organic compounds and tobacco smoke into molecules like oxygen, water, carbon dioxide, nitrates, and sulphates. The whole reaction results in a significant reduction in the concentration of pollutants. It should be noted, however, that most inorganic pollutants and stains, including rust, are not catalysed.

In the past years, these technologies have been applied to glass, ceramic, and cement-based materials. The main applications of $\mathrm{TiO}_{2}$ (traditionally used as white pigment) include pollution remediation, selfcleaning and self-disinfecting surfaces. Along with the advantage of using solar light and rainwater as the driving force, they confer environmentally compatible properties to building materials [4] and landscaping applications. The cement industry [5], has already developed new cement products that offer the possibility to improve environmental quality by decomposing air pollutants in harmless substances, while using a photocatalytic reaction based on a patented technology.

Concrete is a material that allows creating almost every shape: simulations of natural landforms, slopes, hills, retaining walls, stairs, ramps, terraces, urban furniture (Figure 2). It allows the possibility to embed into the landscape various functional, social, cultural and entertaining elements with interesting decorative characteristics and forms.
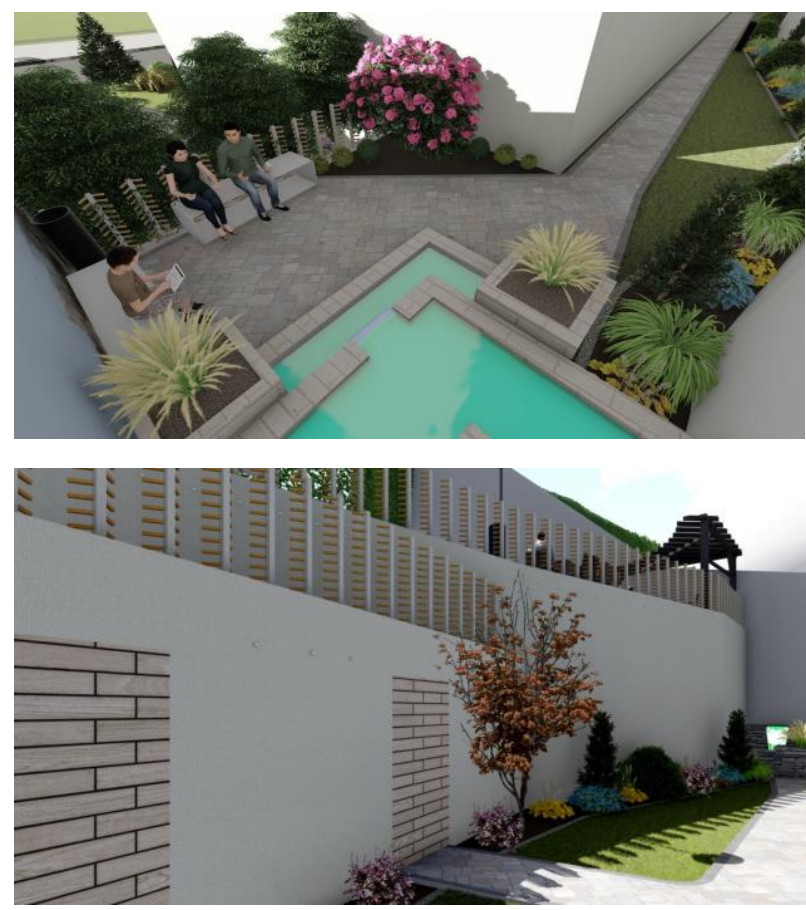

Fig. 2. Decorative elements suitable for self-cleaning concrete.
Paving elements and concrete sidewalk plates are installed in different commercial zones, garden-parks and other pedestrian areas, being used for walk-path surfaces, in a variety of shapes and colours, which expand the design possibilities when implementing traditional or modern architectural solutions. For selfcleaning concrete pavement applications, since photocatalysts transform the pollutants into water soluble compounds, the porosity of the prefabricated concrete elements is very important.

The porosity is affected by aggregate size, water-tocement ratio, and, in general, by the mix design of the concrete. Study results [6] emphasize that the photodegradation of nitrogen oxides $\left(\mathrm{NO}_{\mathrm{x}}\right)$ is related to the porosity of the pavement elements; accordingly, a greater porosity results in increased ability for the removal of nitrogen oxides $\left(\mathrm{NO}_{\mathrm{x}}\right)$. The self-cleaning effectiveness of concrete depends of the titanium dioxide $\left(\mathrm{TiO}_{2}\right)$ content of the cement. Study results [7] reveal that higher $\mathrm{TiO}_{2}$ content in cement increases the selfcleaning activity.

Placed where air quality is greatly affected by vehicle exhaust, noise barriers and visual screens are construction elements with both functional and aesthetic properties, being part of the built environment as well as of the landscaping applications. If made of concrete containing photocatalytic cement, or prepared with the application of surface mortar coatings, or of a photocatalytic concrete cover (which is also more economically feasible [8]) it will allow the oxidation of air pollutants to occur on their surface, along with selfcleaning characteristics and impact on deteriorated air quality in urban environments.

Strategic placement and selection of plant species within an architectural project to highlight and enhance aspects of spatial design produce many daily benefits. Concrete-made interior surfaces (used for vertical gardens, plant storing arrangements), may be subject of self-cleaning characteristics (i.e. air purification) by using the photocatalytic oxidation [9], to destruct volatile organic compounds (VOCs) in indoor air.

\section{Application of self-cleaning concrete elements in design - Case study}

The path of a landscape project from the beginning to its end typically contains the following four major phases (each with its own agenda of tasks and issues): initiation, planning, implementation, and closure. The environmental compatibility for construction and landscaping projects is revealed through active multidisciplinary collaboration, from the design study and preliminary design phases, to execution and supervision, all the way to project completion [10]. Architectural characteristics have to be preserved, landscape design objectives have to be accomplished, and innovative materials, methods and features have to be implemented. In this regard, with respect to regulations, every design theme gives freedom of choice and allows guidance through selection of plants, decorations, shapes, structures and materials. 
Figure 3 presents the large application possibilities of self-cleaning concrete related to often encounter landscaping demands.
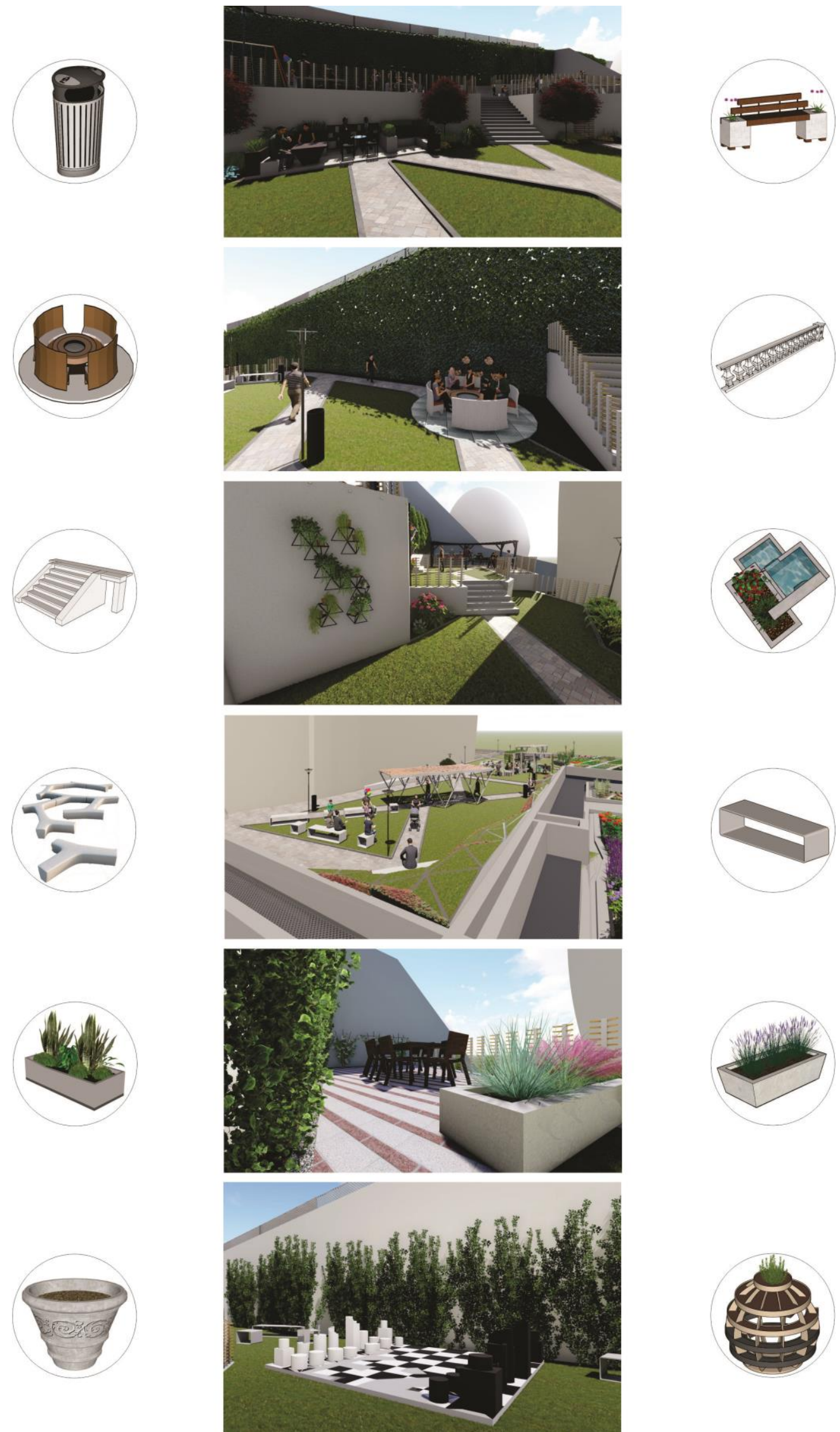

Fig. 3. Landscaping design proposals for functional and decorative applications of self-cleaning concrete elements. 


\section{Conclusions}

The sustainable building concept focuses on the importance of an environment-friendly management of materials throughout their entire life-cycle, from resource extraction, during the fabrication phase, on-site installation, use, maintenance and post-utilization. Using sustainable building materials contributes to conservation of natural resources along with the protection of landscape and its natural balance [11]; it helps to reduce pollution, to achieve energy savings, and to provide a cleaner and healthier living environment.

The use of concrete for the decorative landscape elements is both widely applicable, as well as custommade, due to the durability and shape adaptability qualities of this material [12]. To be effective (i.e. to react with sun light and also to reduce cost) it is more useful when cement with addition of $\mathrm{TiO}_{2}$ is added in surface coating or in the form of concrete cover, rather than being mixed into the construction concrete.

Based on experimental evidence regarding the ability to carry out self cleaning by reaction with compounds responsible for surface finish degradation, building elements containing cement with addition of $\mathrm{TiO}_{2}$ can maintain their aesthetic appearance over time [13]. The lasting performance of photocatalytic activity was assessed [14] during one year of outdoor exposure trial and $2000 \mathrm{~h}$ of accelerated ageing in a chamber with UV radiation and condensation cycles. Results showed that photocatalytic activity on concrete was unaltered.

The constructive and compositional landscaping design solutions depend by their placement in combination with vegetation, relief, walkways, patio areas, and many more locally arising particular details. Along with the addition of photocatalysts to concrete, environmentally compatible materials are created, which can reduce pollution and act like self-cleaning surfaces, also diminishing maintenance related costs.

\section{References}

1. Y. Ohama, D.V. Gemert, Application of Titanium Dioxide Photocatalysis to Construction Materials, State of the Art Report of the RILEM Technical Committee 194-TDP, Springer Dordrecht Heidelberg London New York (2011).

2. A. Fujishima*, T.N. Rao, D.A. Tryk, Titanium dioxide photocatalysis, Journal of Photochemistry and Photobiology C: Photochemistry Reviews 1 (2000) 1-21.

3. A. Beeldens, An environmental friendly solution for air purification and self-cleaning effect: the application of $\mathrm{TiO} 2$ as photocatalyst in concrete, Proceedings of 10th International Symposium on Concrete Roads, Belgian Road Research Centre Brussels, Belgium (2006).

4. J. Chen, C. Poon, Photocatalytic construction and building materials: From fundamentals to applications. Building and Environment, 44, (2009) 1899-1906.

5. Hanson Cement, TioCem - Reducing pollution in the urban environment, www.hanson.co.uk.

6. C.S. Poon, E. Cheung, NO removal efficiency of photocatalytic paving blocks prepared with recycled materials. Construction and Building Materials, Vol. 21, No. 8, (2007) pp. 17461753.
7. F. Pacheco-Torgal, S. Jalali, Nanotechnology: advantages and drawbacks in the field of construction and building materials, Construction and Building Materials, V. 25, pp. 582-590 (2011).

8. C.J. Churchill D.K. Panesar, Life-cycle cost analysis of highway noise barriers designed with photocatalytic cement, Structure and Infrastructure Engineering, Maintenance, Management, Life-Cycle Design and Performance, Vol. 9, 10 (2013) pp. 983-998.

9. J. Zhao, X. Yang, Photocatalytic oxidation for indoor air purification: a literature review. Building and Environment, V. 38, No.5 (2003) pp. 645-654.

10. A.T. Mircea, Selecting Environmentally Compatible Materials for Priority Integration into the Design Process, 17th International Multidisciplinary Scientific Geo Conference SGEM 2017, Vol. 17, 62, Section Green Buildings, Technologies and Materials, Albena, Bulgaria, pp. 409-416. (2017) doi: 10.5593/sgem2017/62/S26.052.

11. A.T. Mircea, Study upon Applying Multi-Criteria Analysis to the Selection of Building Materials, 28th IBIMA Conference on Vision 2020: Innovation Management, Development Sustainability, and Competitive Economic Growth, Seville, Spain (2016).

12. EN 1992-1-1:2004 Eurocod 2: Design of concrete structures - Part 1-1: General rules and rules for buildings (2004).

13. L. Cassar, Cementitious materials and photocatalysis, Congress of International Glassfibre Reinforced Concrete Association, Prague (2008) pp. 1-7.

14. P.M.Carmona-Quiroga, S.Martínez-Ramírez, H.A. Vilesa, Efficiency and durability of a self-cleaning coating on concrete and stones under both natural and artificial ageing trials, Applied Surface Science, Vol. 433, (2018), pp. 312-320.

*Renderings by the author. 